\title{
Antifungal Chemotherapeutics
}

\author{
Vladimir C. Krcmery, Jr. \\ Department of Pharmacology, St Elizabeth University, School of Health Care, Bratislava, Slovak Republic
}

\section{Key Words}

Antifungals $\cdot$ Azoles $\cdot$ Echinocandins $\cdot$ Fungal

infections - Treatment strategies

\begin{abstract}
This review addresses trends in outcome and risk factors for invasive fungal infections, current antifungal agents and new therapeutic strategies. Current prospects for new therapies rest upon caspofungin, the first of a new class of antifungal molecules, the echinocandins, and new extended-spectrum azoles, voriconazole, posaconazole and ravuconazole. Approval by the Food and Drug Administration of the USA and the European Medicine Agency was given in 2001-2002 to voriconazole and caspofungin. Voriconazole clearly demonstrated a decrease in mortality in invasive aspergillosis and fusariosis fungal infections.
\end{abstract}

Copyright $(2005$ S. Karger AG, Basel

\section{Introduction}

With the advent of the acquired immunodeficiency syndrome (AIDS) and advancing medical technology (organ transplantation, radiochemotherapy, dialysis and other procedures), fungal infections are assuming increasing prominence and are associated with considerable mortality.

A 'wonder drug' to prevent or cure all invasive fungal infections (IFI) does not exist. All drugs currently avail- able have both benefits and drawbacks. Unfortunately, amphotericin B (AmB), the agent with the broadest spectrum of activity, is associated with considerable toxicity. The triazoles, for example fluconazole (FLU) or itraconazole (ITRA), have clearly demonstrated their value in the antifungal field, but have not fulfilled all hopes. A truly safe and effective fungicidal drug does not yet exist.

Current prospects for new therapies therefore depend upon caspofungin, the first of a new class of antifungal molecules, the echinocandins, and new extended-spectrum azoles: voriconazole, posaconazole and ravuconazole. In 2001-2002, approval by the Food and Drug Administration (FDA) and European Medicine Agency (EMEA) was given to voriconazole and caspofungin. Voriconazole demonstrated something that was not clearly marked before, a decreased mortality in fatal IFI, e.g. in aspergillosis and fusariosis.

This review addresses trends in outcome and risk factors for IFI, current antifungal agents, and new therapeutic strategies.

\section{Resistance to Antifungal Agents}

Candida albicans is usually susceptible to all antifungal agents [1-12]. A recent study on the susceptibility of C. albicans to FLU showed $99.7 \%$ susceptibility in Europe and $98.1 \%$ in the US (more than 15,000 strains tested) $[2,5]$. Susceptibility to AmB and nystatin is up to $100 \%$, and susceptibility to ketoconazole and ITRA is

\section{KARGER}

Fax +4161306 1234

E-Mail karger@karger.ch

www.karger.com
(C) 2005 S. Karger AG, Basel

1011-7571/05/0143-0125\$22.00/0

Accessible online at:

www.karger.com/mpp
Vladimir C. Krcmery, Jr, FACP, FRCP

Department of Clinical Pharmacology

St. Elisabeth Cancer Institute, Heydukova 10

SK-81250 Bratislava (Slovak Republic)

Tel./Fax +421 25292 4308, E-Mail vladimir.krcmery@spamba.sk 
also very high (95-100\%) [5]. Development of resistance towards 5-fluorocytosine (5-FC) is rapid, but a majority of $C$. albicans infections are still susceptible to all available drugs. The most recent study of Pfaller and the Mycoses Study Group [13] on more than 1,000 C. albicans bloodstream isolates showed no increase in resistance in 1999 in comparison to 1990.

In the last 5 years, two studies (both in cancer patients) have tried to address speciation and antifungal resistance. One was a European prospective study [14] and the other a single-institution-based retrospective candidemia surveillance [9]. This latter US study, involving 140 cases, showed that fungemias from non-albicans Candida (NAC) spp. had similar outcomes to $C$. albicans fungemias [9]. In contrast, the larger prospective multicenter study conducted by the European Organization for Research and Treatment of Cancer [14] showed that candidemias due to C. glabrata (odds ratio, OR, 2.08), C. tropicalis (OR 1.8) and C. krusei (OR approximately 1.6) had inferior outcomes in comparison to C.albicans (OR 1.00) and C. parapsilosis (OR 0.48). Other studies on C. krusei, C. lusitaniae, C. glabrata and C. parapsilosis [7-11, 1518] have investigated comparative virulence and mortality from NAC species. These studies showed higher mortality from NAC in comparison to C. albicans $[14,7-11$, $15]$.

The in vivo-in vitro correlations between outcome of fungal infections and susceptibility or resistance of causative fungal isolates have been documented in adult HIVpositive patients $[4,6,19]$. There are still controversies concerning the relationship between in vitro susceptibility of Candida spp. and clinical outcomes in non-HIV patient populations $[7-13,15]$. One study showed a correlation between minimal lethal concentration (MLC) and minimal fungicidal concentration to $\mathrm{AmB}$ and microbiological and clinical failure [3]. A similar correlation was shown with FLU [18]. A partial relationship between clinical course and mortality of candidemia and in vitro susceptibility to FLU was shown in two studies $[8,12]$, but not observed in another [5]. All published studies on this issue dealt with Candida spp. in adults. Studies in children, mainly in neonates with fungemia and in nonHIV individuals with mucosal/skin mycology are expected to address correlations between outcome and resistance. Furthermore, breakpoints (minimal inhibitory concentrations, MICs) for antifungals should be derived from those studies or slightly adapted, if necessary [1-3, $12-14,18,19]$.

\section{'Old' Therapeutic Molecules}

\section{Polyenes; Amphotericin B, Amphotericin B- Deoxycholate and Nystatin}

\section{Amphotericin B: Activity, Toxicity}

$\mathrm{AmpB}$ has long been a mainstay of therapy for systemic fungal infections. However, it is associated with many adverse effects, notably a variety of electrolyte abnormalities (including hypokalemia, hypomagnesemia, hypernatremia and metabolic acidosis) and most importantly, acute renal failure [20-25]. It appears that nephrotoxicity is mediated, in part, through a direct toxic effect on renal tubular cells, resulting in acute tubular necrosis [26]. Vasoconstriction is also induced, with both processes reducing glomerular filtration [26-30]. No specific treatments are available to reverse the acute renal failure associated with $\mathrm{AmB}$, although salt loading (when tolerated) has been used with some success as a prophylactic measure [31-33]. This acute renal failure is often dose limiting, is sometimes irreversible, and can prolong hospitalization and increase treatment costs. The reported frequency of acute renal failure associated with $\mathrm{AmB}$ has varied widely $[25,29]$. A meaningful decrement in renal function has been reported to occur in up to $80 \%$ of patients who receive the drug, and is almost inevitable in patients who receive a cumulative dose of $>5 \mathrm{~g}$. However, much smaller total doses are currently used. For example, in one recent study of 102 patients in a community hospital, the mean cumulative dose of AmB used was $<200 \mathrm{mg}$, and the maximum dose was $840 \mathrm{mg}$. In this population only $15 \%$ of the patients developed acute renal failure [25]. Considering the frequency of this complication, relatively little data are available regarding the mortality rates associated with acute renal failure from any cause [34, 35], and it remains to be determined whether patient mortality due to renal failure is caused by the underlying disease or results directly from this complication.

\section{Amphotericin B: Resistance}

AmB-deoxycholate or conventional AmB has been used since 1951 . The drug has fungicidal activity towards most Candida isolates and species (MIC $<0.1 \mu \mathrm{g} / \mathrm{ml}$ ) if the serum concentration exceeds 10-16 times MIC. In isolates with MIC of $0.5-2 \mu \mathrm{g} / \mathrm{ml}, \mathrm{AmB}$ will show fungistatic activity. Clinical resistance may be seen in most cases infected with Candida strains that demonstrate MIC $>0.5 \mu \mathrm{g} / \mathrm{ml}$. Although AmB shows in vitro activity against most pathogenic fungi, there are notable exceptions. Most Fusarium spp., Pseudallescheria boydii and 
Paecilomyces varioti are resistant both in vitro and clinically (MIC $>2.2-8 \mu \mathrm{g} / \mathrm{ml}$ ). Also, Trichosporon spp. and some strains of Aspergillus nidulans, Aspergillus terrerus, $C$. lusitaniae and C. rugosa show secondary resistance to AmB. Resistance is seen in 1-5\% of C. lusitaniae, C. guillermondii and $C$. rugosa cases $[3,8,12]$.

\section{Amphotericin B: Applications}

Standard indications for intravenous AmB are systemic fungal infections due to the most common fungal organisms (apart from Trichosporon spp. and Ps. boydii). Empiric therapy of febrile neutropenia is also a very important indication for AmB $[8,17]$. Oral AmB was formerly used for prophylaxis, or selective decontamination, but has been replaced with FLU following bone marrow transplantation or in patients with acute leukemia [16]. For cryptococcal meningitis, AmB in combination with 5-FC is indicated. The standard dose of AmB is 0.7$1 \mathrm{mg} / \mathrm{kg} /$ day in adults and $1-1.5 \mathrm{mg} / \mathrm{kg} / \mathrm{day}$ in children . Lipid formulations of AmB have been developed [36-39] (see below) with reduced toxicity facilitating administration of $3-5 \mathrm{mg} / \mathrm{kg} /$ day.

\section{Lipid Formulations of Polyenes}

Although AmB and nystatin are antifungal agents with the broadest spectra of activity, the toxicity of polyenes may prevent their use at sufficient dosages [33-36]. Clinical failure is common for patients infected with organisms susceptible in vitro because patients are either under-dosed, or are unable to complete the treatment due to kidney failure (acute or chronic) [40, 41]. Three new lipid-based formulations for polyenes have been developed and introduced from 1990 to 1998 in response to these problems [37-39, 42]. These are (i) ambisome, a 'true' liposomal formulation of AmB, (ii) Nexstar (AmBisome, Nexstar) AmB in colloidal dispersion (ABCD; Amphocil, Zeneca) and (iii) AmB in lipid complex (ABLC, Abelcet developed by Enzon, Liposome) and currently offered by Enzon. In addition, liposomal nystatin is under investigation (Nyotran).

In several patients, a dosage of $4-10 \mathrm{mg} / \mathrm{kg} /$ day of ABLC was used in AmB-refractory mycosis [36], contrasting with a recommended dose for ambisome of 1$3 \mathrm{mg} / \mathrm{kg} /$ day and of $2-4 \mathrm{mg} / \mathrm{kg} /$ day ABCD (Amphocil). There were no differences in acute toxicity (chills, fever and shivers) which were lowest (according to randomized controlled studies [38]) in ambisome, which is a 'true liposomal AmB', and somewhat higher in ABLC [38]. Kidney and liver toxicity was significantly lower for all lipid formulations than in conventional AmB therapy [38].
Specific indications for lipid formulations of $\mathrm{AmB}$ are: preexisting renal failure, acute toxicity or chronic nephroor hepatotoxicity during treatment with $\mathrm{AmB}$ and fungal infection that does not respond to treatment with either AmB or FLU.

Recommended indications for the systemic use of lipid formulations are: (a) fungemia caused by species resistant in vitro to AmB and/or FLU (C. krusei, C. lusitaniae); (b) invasive aspergillosis (IA) when proven or highly suspected (positive bronchoalveolar lavage, antigens or typical CT scan); (c) fusarial and mucor infections (indicated in combination with granulocyte macrophage colony stimulating factor, GM-CSF, therapy and/or surgery), and (d) any IFI not responding to AmB or FLU; lipid formulations of $\mathrm{AmB}$ or voriconazole are the drugs of choice for second-line therapy.

Liposomal amphotericins are significantly more expensive than conventional AmB. Evaluation of costs and the risks of AmB toxicity, along with the relative efficacy and costs of other antifungal agents, could help in decision-making about which patients should receive newer, more costly but less nephrotoxic agents as alternatives to AmB [42]. Because of costs, lipid-based formulations are not indicated for empiric therapy of febrile neutropenia and/or prophylaxis of fungal infections in leukemia or bone marrow transplantation [38].

\section{Antimetabolite Drugs: 5-Fluorocytosine}

5-FC is the only antimetabolite currently used as a systemic antifungal agent (Ancotil, Roche) which is active in vitro against Candida spp., Cryptococcus neoformans and a variety of yeasts and molds. This agent is not used in monotherapy but only in combination with $\mathrm{AmB}$ (see section on combination antifungal therapies) or FLU [43]. The main indication for 5-FC is treatment of cryptococcal meningitis (in combination with $\mathrm{AmB}$ ). $\mathrm{FC}$ is no longer used in combination with $\mathrm{AmB}$ for empiric treatment of febrile neutropenia, since monotherapy with AmB showed sufficient efficacy in empiric therapy in cancer patients and in cases of neutropenic fever not responding to antimicrobials.

\section{Triazole Drugs}

\section{Fluconazole}

FLU has excellent in vitro activity against $C$. albicans [44]. FLU can also be effective against some NAC species, 
including C. parapsilosis, C. tropicalis and C. glabrata, although higher doses may be required $[44,45]$. FLU shows excellent penetration into cerebrospinal fluid, and the peroral form has high bioavailability.

FLU is effective against infections at a wide range of body sites and tissues, irrespective of the patient's immune status [46-48]. Indications in adults include vaginal [47, 49], mucosal [48], dermal and systemic candidosis [46, 49-53]. Prophylactic administration of FLU can be useful in patients considered at risk of fungal infections as a consequence of neutropenia following chemotherapy or radiotherapy [54-58]. Experimental evidence [59] and clinical case reports [60] suggest that prophylaxis with FLU may be useful in preventing infections associated with $C$. albicans.

Fluconazole is suitable and effective for use in children [61-69], but higher dosage adjustments should be made. In the elderly, normal adult dose regimens should be used if there is no evidence of renal impairment. In those with renal impairment, no adjustments in single-dose therapy are required; for multiple-dose therapy, either the dosage interval should be increased or the daily dosage should be reduced $[46,69]$.

\section{Itraconazole}

ITRA shows in vitro activity against a greater range of Candida species than FLU [70]. However, ITRA does not penetrate into the cerebrospinal and peritoneal fluid, and its bioavailability is poor. ITRA capsules are effective and indicated for the treatment of a number of localized and systemic fungal infections in adults, irrespective of the immune status of the patient [71]. These include vulvovaginal [72] and oropharyngeal candidosis. Because of its lipophilicity, ITRA distributes to the nails, and the capsule formulation is effective in the treatment of onychomycosis [73]. ITRA capsules can be used as maintenance therapy in patients with AIDS and as prophylaxis before expected neutropenia. As absorption is often impaired, blood monitoring should be performed and the dose increased if necessary.

There are inadequate data concerning ITRA capsule formulations, or in solution, in children $(<12$ years) and in the elderly for its use to be recommended in these special patient populations unless potential benefits outweigh the potential risks [70].

At present, ITRA solution, in a dosage of $200 \mathrm{mg}$ once daily or $100 \mathrm{mg}$ twice daily for 1 week, repeated as necessary, is indicated solely for the treatment of oral and esophageal candidosis in HIV-positive or immunocompromised adults.

\section{‘New' Molecules}

\section{Echinocandins: Caspofungin and Anidulafungin}

Pneumocandins and echinocandins represent an entirely new class of antifungal molecules. Caspofungin (Cancidas, Merck) is currently the only available echinocandin. Micafugin (Fujisawa) will probably be introduced into clinical practice in the near future and a related molecule, anidulafungin is in phase II clinical research. Candinsoperate at two sites in fungal metabolism, $D$-glucan synthesis of the cell wall and ergosterol synthesis $[74,75]$, acting somewhat more slowly $(5-7 \mathrm{~h})$ than polyenes and azoles. The antifungal spectrum of caspofungin involves all yeasts and molds apart from Cryptococcus (cell wall lacks $D$-glucan), and it is also active against Aspergillus, but activity is decreased compared to voriconazole, and against $P$. carinii and $P$. jirovecii $[74,75]$.

\section{Pharmacological Profile}

Plasma clearance of caspofungin is $10-12 \mathrm{mg} / \mathrm{min}$, protein clearance $96 \%$ and elimination half-life is $9-11 \mathrm{~h}$ through liver metabolism. Interaction with cyclosporin may result in elevation in liver enzymes [76, 77], and tacrolimus concentrations should be measured. Caspofungin is currently only available as intravenous infusion; the daily dose is $50-70 \mathrm{mg} / \mathrm{kg}$ for adults and $70-100 \mathrm{mg} / \mathrm{kg}$ for children. In contrast to $\mathrm{AmB}$, no dose reduction in kidney failure is necessary [78].

\section{Clinical Application}

Caspofungin was compared to AmB in HIV-positive patients with candidal esophagitis [79] with $89 \%$ efficacy $(66.7 \%$ in AmB-treated patients); caspofungin $50 \mathrm{mg}$ once daily showed $85 \%$ efficacy compared to $82 \%$ for FLU $200 \mathrm{mg}$ once daily [80]. In a study of refractory (not responding to AmB or other agents) aspergillosis, a $41 \%$ response rate was observed in this prognostically inferior group of patients [80]. In the absence of a randomized controlled study on caspofungin versus lipid formulations of $\mathrm{AmB}$ or conventional $\mathrm{AmB}$ in documented aspergillosis, caspofungin was considered as second-line therapy or may be used in combination with $\mathrm{AmB}$, or voriconazole, for IA $[79,80]$. In two further controlled studies $[80,81]$ involving more than 200 patients with IA, responses [82] of 49 vs. $19 \%$ were observed in non-neutropenic patients in favor of caspofungin [81]. 
The most recent study that compared caspofungin with $\mathrm{AmB}$ in the treatment of invasive candidemia was published [83, 84]. Some 224 patients with candidemia were evaluated, and response was $80.7 \%$ (caspofungin) and $64.9 \%(\mathrm{AmB})$. This is to date the largest candidemia study with caspofungin. Finally, a study with a small group of patients using caspofungin in combination with $\mathrm{AmB}$ has been published [85]. Caspofungin was documented to be effective in candidemia or esophageal candidiasis as monotherapy, and for aspergillosis either as a second-line agent for non-responders or in combination with AmB (conventional or lipid formulation). Further studies are expected to evaluate the role of caspofungin in IA as monotherapy as well as in pediatrics, where no studies are available.

\section{Triazoles: Voriconazole, Posaconazole and Ravuconazole}

\section{Voriconazole}

Voriconazole (UK-109,496), a novel wide-spectrum triazole antifungal agent, is active in vitro against Aspergillus species for which the geometric mean MIC is $0.4 \mathrm{mg} / \mathrm{l}$, which compares favorably with that of $\mathrm{AmB}$ [86-88]. The drug is fungicidal in vitro for a majority of isolates and can be given both orally and intravenously, making switch therapy easier [86-94]. Several studies evaluated the clinical efficacy and safety of voriconazole in the treatment of acute IA candidemia and also the empiric therapy of IFI in neutropenic and other immunocompromised patients [93-95].

Denning et al. [96] evaluated the efficacy and safety of voriconazole in acute IA in an open, noncomparative multicenter study. Immunocompromised patients with IA were treated with intravenously administered voriconazole $6 \mathrm{mg} / \mathrm{kg}$ twice a day twice and then $3 \mathrm{mg} / \mathrm{kg}$ twice daily for 6-27 days, followed by $200 \mathrm{mg}$ administered orally twice daily for up to 24 weeks. Response was assessed by clinical and radiographic changes. A total of 116 patients were assessable; IA was proven in $48(41 \%)$ and probable in 68 patients. Voriconazole was given as primary therapy in 60 (52\%). Good responses were seen in 56 patients (48\%); 16 (14\%) showed complete response and $40(34 \%)$ partial response. A stable response was seen in 24 patients $(21 \%)$, and $36(31 \%)$ patients failed to respond to therapy. Good responses were seen in $60 \%$ of those with pulmonary or tracheobronchial IA $(\mathrm{n}=84), 16 \%$ with cerebral IA $(\mathrm{n}=$ 19), $58 \%$ with hematologic disorders $(n=67)$, and $26 \%$ of allogeneic stem cell transplant recipients $(n=23)$.
Herbrecht et al. [97] enrolled a total of 144 patients with definite or probable aspergillosis in a voriconazole treatment group and 133 patients in an AmB group; patients received at least one dose of treatment. In most of the patients the underlying condition was allogeneic hematopoietic-cell transplantation, acute leukemia, or other hematologic diseases. At the 12-week follow-up, there were successful outcomes in $52.8 \%$ of the patients in the voriconazole group (complete responses in $20.8 \%$ and partial responses in $31.9 \%$ ) and in $31.6 \%$ of those in the $\mathrm{AmB}$ group (complete responses in $16.5 \%$ and partial responses in $15.0 \%$; absolute difference, 21.2 percentage points; $95 \%$ confidence interval, 10.4-32.9). The survival rate at 12 weeks was $70.8 \%$ in the voriconazole group and $57.9 \%$ in the AmB group (hazard ratio, $0.59 ; 95 \%$ confidence interval, 0.40-0.88). Voriconazole-treated patients had significantly fewer severe drug-related adverse events, but transient visual disturbances were common with voriconazole (occurring in $44.8 \%$ of the patients). In patients with IA, initial therapy with voriconazole led to better responses, improved survival and resulted in fewer severe side effects than the standard approach of initial therapy with AmB.

Walsh et al. [98] published a study on empiric therapy of febrile neutropenia with voriconazole in comparison to liposomal AmB. This large study included 415 and 422 patients randomized to receive empiric therapy (either voriconazole or ambisome) for febrile neutropenia not responding to antibiotics. Significantly fewer breakthrough fungemias $(p<0.02)$ overall and in high-risk patients $(\mathrm{p}<0.003)$ were observed in those receiving voriconazole.

\section{Posaconazole and Ravuconazole}

Posaconazole and ravuconazole are the newest azoles that are currently in phase II-III studies and which will probably come to clinical use in 2005 [99-108].

Posaconazole is a new triazole antifungal agent synthesized by the Schering-Plough Research Institute. Preclinical studies of this agent conducted in various countries, including Japan, have shown excellent in vitro and in vivo antifungal activities [99-103] also against mucormycosis. Before embarking on clinical trials in Japan, a basic study to confirm the in vitro antifungal activities was performed [100, 101]. Ravuconazole showed very good in vitro activity against NAC species. However, results from clinical studies are not currently complete. 


\section{New Strategies in the Management of IFI}

\section{Antifungal Combination Therapy}

Antifungal combination therapy is based on (i) in vitro studies on synergism of particular antifungals, (ii) animal models, and (iii) clinical experience based on case reports, retrospective observational studies or prospective clinical trials. The majority of applications are based on the treatment of fungal infections not responding superficially to standard antifungal therapy (e.g. cryptococcosis, some NAC species) or caused by multiresistant organisms (C. krusei, C. glabrata, Fusarium spp.) and in settings associated with high mortality (aspergillosis). It should be borne in mind that a truly synergistic effect at the level of fungal cells is not the only prerequisite for a beneficial effect in human chemotherapy [109].

The first antifungal combination to be tested in controlled clinical trials was 5-FC $+\mathrm{AmB}$ which was studied in patients with cryptococcal meningitis. Meningeal cryptococcosis was chosen because it is always lethal and needs an aggressive, preferentially fungicidal, therapy.

The combination of 5-FC + FLU to treat cryptococcal meningitis in AIDS patients [110] demonstrated clinical success that was significantly greater than previously reported for AmB or FLU monotherapy. A total of $75 \%$ of the patients had negative cultures in the cerebrospinal fluid 10 weeks after initiation of therapy, while only 35$40 \%$ of the cultures became negative under monotherapy. The overall clinical success rate was $63 \%$ with the combination. However, toxic side effects that were sufficiently severe to lead to withdrawal of 5-FC were observed in $28 \%$ of the patients. Apart from cryptococcal meningitis, $\mathrm{AmB}+5$-FC has been used in the treatment of fungemia caused by resistant Candida spp. Combination therapy should be used only for cryptococcal meningitis.

Combination therapy with 5-FC $+\mathrm{AmB}$ has clearly established its beneficial value for human chemotherapy and is still used for deep-seated mycoses in severely immunosuppressed patients. The interaction of azoles and polyenes clearly varies by fungus, test model and drug. No general rule concerning the concomitant or sequential use of these drugs exists; each case requires individual study [110-112].

\section{Immunomodulators}

Various cytokines have been produced using biotechnological methods. Most of these factors have been thor- oughly investigated in vitro and in vivo to define their role in defense against fungal infections. Some were found to show a depressive effect increasing the acute course of fungal infection, for example interleukin 4 in candidosis [113]. Most immunomodulators, however, have the capacity to increase host defense and therefore cause an increase in survival time or a decrease in the fungal burden $[114,115]$.

The most promising immunomodulators for fungal infections appear to be the G-CSF, GM-CSF and M-CSF. The available in vitro and animal data clearly show that addition of various immunomodulators augment the beneficial effect of conventional antifungal agents. The data from preliminary human studies combining cytokines with traditional antifungal therapy generally suggest that augmentation of the immune system complements the effect of antifungal therapy. For example, reversal of immunodeficiency is essential for successful recovery from IA. The mortality rate and duration of granulocytopenia can be decreased by the addition of G-CSF or GM-CSF to conventional antifungal therapy, leading to more rapid and complete recovery [113-115].

Most clinical work has been done with the various colony-stimulating factors (G-CSF, GM-CSF and M-CSF). Several encouraging reports exist describing the use of GCSF in patients with fungal infections and underlying conditions that cause neutrophilic deficiency, such as aplastic anemia or chronic granulomatous disease $[116,117]$.

\section{Surgical Treatment of IFI}

Several IFI cannot be cured just with antifungals even when combined with immunomodulators [118]. (i) In all cases of fungemia related with a foreign body (e.g. shunt infection or prosthetic cardiac valves), the foreign device must be surgically removed. Surgical intervention is essential for a better outcome, reduced duration of fungemia and reduced morbidity and mortality. Antifungal chemotherapy should accompany the surgical intervention. (ii) In metastatic complications of candidemia (e.g. brain or liver abscess) surgical punctio and drainage is essential. (iii) In IA, surgery is important in the treatment of pulmonary diseases which present bleeding complications, and it reduces significantly mortality as a result of aspergillosis erosion of lung vessels. Radical resection of infected lung tissue is often life-saving surgery, however it requires an experienced surgeon and massive hematologic support because of concomitant pancytopenia. (iv) In rhinocerebral or ophthalmic mucomycosis, radical 
resection or vitrectomy (ophthalmic) followed by lipid formulations of $\mathrm{AmB}$ or voriconazole is the only possible therapy, reducing mortality from 100 to $50-75 \%$. (v) In aspergillosis sinusitis, surgical drainage is not only used to prevent sinoantral IA, but also to prevent the hematogenous spread during subsequent immunosuppression (e.g. in leukemia, bone marrow transplantation and graftversus-host disease).

Surgery performed in ii-v is an important therapeutic strategy to treat or prevent IFI, and is followed or accompanied by antifungal chemotherapy. Initial (empiric) therapy of IFI in surgical patients has also been studied [118-122].

\section{Specific Strategies in Pediatrics}

Several risk factors and the epidemiology of invasive candidiasis are different in children in comparison to adults. Also, the outcome of Candida infection in children is better. Pharmacokinetic properties of new azoles are different in small children and especially in neonates compared to adults. In large multicenter studies examining new antifungal agents, data in children and adults are not separately evaluated; therefore it is difficult to assess the activity of those compounds in children. Data from adults may be extrapolated to older children and adolescents but not to neonates. Some retrospective or open studies on FLU and a lipid formulation of AmB in children are available to assess activity and safety of those drugs in the treatment of systemic candemiasis in pediatrics [123-130].

There are differences in the pharmacokinetics of antifungal drugs in children. This phenomenon can be seen in many antimicrobial agents, where the half-life is shorter and $C \max$ may be lower than in adults. This was documented for FLU [124] as well as the lipid formulation of AmB [128]. Therefore, dosing intervals of FLU in neonates and small children $<5$ years of age should be shorter [125-126]. Pharmacokinetics of lipid formulations of AmB, mainly of ABLC, was also studied in neonates, where different dosing intervals were examined. Compared to adults, children older than 3 months of age manifest more rapid clearance of AmB [129]. Premature neonates are characterized by extreme individual variation in the distribution and clearance of $\mathrm{AmB}$, and thus individual serum levels cannot be predicted with certainty [129]. Some neonates continue to accumulate AmB during the course of therapy, an observation suggesting that they require a dose interval of more than $24 \mathrm{~h}$. AmB toxicity is less severe in infants and children than in adults, probably because of the more rapid clearance of the drug in children $[126,127]$. However, in children $>5-$ 10 years old, the pharmacokinetic parameters of antifungals are similar in children and adults. Concerning toxicity, generally liver and kidney toxicity of $\mathrm{AmB}$ is lower in children than in adults. Children usually tolerate higher doses of $\mathrm{AmB}(1.5 \mu \mathrm{g} / \mathrm{kg} /$ day of $\mathrm{AmB}$ or $5-10 \mu \mathrm{g} / \mathrm{kg} / \mathrm{day}$ of lipid formulations of AmB [127]). The safety of azoles is higher than, or similar to, adults, even in premature neonates. No significant toxicity of higher doses of FLU was observed in children [123-125].

\section{In vivo and in vitro Correlation}

Because of advances in therapeutic interventions as well as the AIDS epidemic, rates of fungal infections have shown manifold increases in recent years [131, 132]. While AmB and 5-FU were for a long time the only available systemic antifungal agents, both of these drugs are difficult to use; the pharmaceutical industry has responded to the demand for new therapies for fungal infections with the introduction of ketoconazole, ITRA, FLU, and the lipid formulations of AmB. The National Committee for Clinical Laboratory Standards has proposed standardized methodology for antifungal susceptibility testing and tentative interpretative breakpoints for the triazole agents. However, the methodology remains to be validated for AmB testing $[3,18,19]$.

Unlike in vitro antibacterial susceptibility testing, which has been useful in the selection of optimal antibacterial therapy, antifungal susceptibility testing has been hampered by a number of limitations, including the lack of standardized methodology and in many cases the lack of correlation between in vitro results and in vivo outcomes [5, 131-133].

There have been several studies showing partial or entire correlation between resistance and infection outcome. However, the majority of these studies $[4,6,19]$ documented this relationship on HIV-positive individuals with candidiasis in the setting of patients treated with FLU. Other factors associated with inferior outcome (therapy failure or relapse) were prior therapy with FLU, CD4 cell count, and progression of AIDS.

In all those studies, patients with MICs to FLU of 32 or $64 \mu \mathrm{g} / \mathrm{ml}$ and more, and even in the group with MICs of $8-16 \mu \mathrm{g} / \mathrm{ml}$, were associated with more failures, prolonged therapy and more relapses. Increasing the dose of FLU to $400-600 \mathrm{mg}$ /day showed no effect on outcome, because the relapses occurred late. Some of those studies 
assessed the MICs to other antifungal agents such as AmB, 5-FU or ITRA. However, at least two other studies in HIV-negative patients (one cancer and one surgery + intensive care unit patients) were published in 19951998 and demonstrated an in vitro-in vivo correlation in proven fungal infection (fungemia) [12].

In the first study, Nguyen et al. [3] examined more than 100 fungemias in cancer patients caused by Candida spp. and found two correlations between the in vitro susceptibility and clinical outcome. Cases with minimal bacterial inhibition for AmB of $1 \mu \mathrm{g} / \mathrm{ml}$ and those with MLC $\geq 0.5 \mu \mathrm{g} / \mathrm{ml}$ were both associated with an inferior outcome. This correlation was highly significant $(p<0.001)$ for minimal bacterial inhibition and MLC, but not for MIC.

In the second study, collecting 264 fungemias in intensive care unit and surgery patients including those with cancer (mixed patient population), patients with candidemia caused by organisms with MICs to FLU $>32 \mu \mathrm{g} / \mathrm{ml}$ had higher mortality than individuals infected with susceptible Candida spp. [12].

Beyond the last two fungemia studies (with 100 and 264 cases), the largest multicenter fungemia study in the US was only for in vitro-in vivo correlation among more than 200 candidemias in cancer patients [5]. The authors even observed that patients infected with Candida spp. with higher MICs to AmB and FLU had better outcomes. However, this association (which may be a surprising one) was statistically insignificant. Therefore, the only correlation drawn from that study was an absence of the relationship of MICs to FLU and AmB and the clinical outcome of candidemia in both small and attributable mortality.
Finally, a large multicenter study testing more than 1,000 bloodstream isolates of Candida spp. was conducted in the US by Pfaller and the Mycoses Study Group [13]. Despite a correlation in vitro to in vivo activity, no trends towards an increase of resistance to FLU in Candida spp. within the last 5 years was observed. Several other studies observed stable resistance to AmB and FLU despite $50(\mathrm{AmB})$ or 15 (FLU) years of clinical use, but correlations of clinical outcome and resistance were not studied [131, 132].

\section{Conclusions}

In this review, only some of the current therapeutic promises and dilemmas in the management of IFI have been discussed. Some hope has been observed with respect to outcome. After a decade of 'standstill' in the antifungal armamentarium, several agents are in the pipeline of development in the pharmaceutical industry. However, only two appear to influence mortality (voriconazole and lipid formulations of AmB). Fortunately, at least one molecule has shown an impact on outcome, which is the ultimate goal in the development of antifungal agents.

\section{Acknowledgment}

Drs. J. Korcova, M. Mrazova and E. Buckova are thanked for their assistance in the preparation of the manuscript.

\section{References}

1 Rex JH, Pfaller MA, Galgiani JN, Bartlett MS, Espinel-Ingroff A, Ghannoum MA, Lancaster M, Odds FC, Rinaldi MG, Walsh TJ, Barry AL: Development of interpretive breakpoints for antifungal susceptibility testing: Conceptual framework and analysis of in vitro-in vivo correlation data for fluconazole, itraconazole, and Candida infections. Clin Infect Dis 1997; 24:235-247.

2 Bille J, Glauser MP: Evaluation of the susceptibility of pathogenic Candida species to fluconazole. Fluconazole Global Susceptibility Study Group. Eur J Clin Microbiol Infect Dis 1997;16:924-928.

\footnotetext{
3 Nguyen MH, Clancy CJ, Yu VL, Yu YC, Morris AJ, Snydman DR, Sutton DA, Rinaldi MG: Do in vitro susceptibility data predict the microbiologic response to amphotericin B? Results of a prospective study of patients with Candida fungemia. J Infect Dis 1998;177:425-430.

4 Ruhnke M: Fluconazole resistance in oropharyngal candidiasis in HIV patients. Infection $1995 ; 24: 83$.

$\longrightarrow 5$ Rex JH, Pfaller MA, Barry AL, Nelson PW, Webb CD: Antifungal susceptibility testing of isolates from a randomized, multicenter trial of fluconazole versus amphotericin B as treatment of nonneutropenic patients with candidemia. Antimicrob Agents Chemother 1995; 39:40-44.
}

-6 Tumbarello M, Cardalola G, Taconelli E, Morace G, Posteraro B, Cauda R, Ortma L: Analysis of the risk factors associated with the emergence of azole-resistant oral candidiasis in the course of HIV infections. J Antimicrob Chemother 1996;38:691-699.

7 Krcmery V, Spanik S, Kunova A, Trupl J, Grausova S, Krupova I, Mateicka F, Pichnova E, Grey E, Sabo A: Nosocomial Candida krusei fungemia in cancer patients: Report of 10 cases and review. J Chemother 1999;11:131136. 
-8 Krcmery V, Krupova I, Denning DW: Invasive yeast infections other than Candida spp. in acute leukaemia. J Hosp Infect 1999;41:181194.

$\checkmark 9$ Krcmery V, Mrazova M, Kunova A, Grey E, Mardiak J, Jurga L, Sabo A, Sufliarsky J, Sevcikova L, Sorkovska D, West D, Trupl J, Novotny J, Mateicka F: Nosocomial candidaemia due to species other Candida albicans in cancer patients. Support Care Cancer 1999;7: 428-431.

$\checkmark 10$ Krcmery V, Krupova I, Mateicka F, Jurga L, Sulcova M, Spanik S, Kunova A, Novotny J: Candida glabrata fungemia in a tertiary cancer institution in Slovakia. J Infect Chemother 1999;5:163-167.

11 Krcmery V, Sejnova D, Pichnova E: Breakthrough Candida tropicalis fungemia during ketoconazole prophylaxis in cancer patients. Acta Oncol 1999;38:663-665.

$>12$ Kovacicova G, Krcmery V, and the Fungemia Study Group: Antifungal susceptibility of 262 blood stream yeast isolates from mixed cancer and non-cancer patient population: Is there a correlation between in vitro resistance to fluconazole and outcome of fungemia? J Infect Chemother 2000;6:216-221.

13 Pfaller MA, and the Mycoses Study Group: Antifungal susceptibility of bloodstream isolates from 32 US centres. Diagn Microbiol Infect Dis 1999;40:232-238.

14 Viscoli C, Girmenia C, Marinus A, Collette L, Martino P, Vandercam B, Doyen C, Lebeau B, Spence D, Krcmery V, De Pauw B, Meunier F: Candidemia in cancer patients: A prospective, multicenter surveillance study by the Invasive Fungal Infection Group (IFIG) of the European Organization for Research and Treatment of Cancer (EORTC). Clin Infect Dis 1999;28: 1071-1079.

15 Krcmery V: Candida parapsilosis fungemia in cancer patients. Neoplasma 1999;46:32.

16 Wingard, JR: Importance of Candida species other than C. albicans as pathogens in oncology patients. Clin Infect Dis 1995;20:115-125.

$\checkmark 17$ Abi Said D, Anaissie E, Uzun O, Raad I, Pinzcowski H, Vartivarian S: The epidemiology of hematogenous candidiasis caused by different Candida species. Clin Infect Dis 1997;24: 1122-1128.

-18 Shah PM: Personalized antifungal susceptibility testing. J Antimicrob Chemother 1999;44: 291.

19 Troillet N, Durussel C, Bille J, Glauser MP, Chave JP: Correlation between in vitro susceptibility of Candida albicans and fluconazoleresistant oropharyngeal candidiasis in HIV-infected patients. Eur J Clin Microbiol Infect Dis 1993; 12:911-915.

20 Patterson RM, Ackerman GL: Renal tubular acidosis due to amphotericin B nephrotoxicity. Arch Intern Med 1971;127:241-244.

-21 Douglas JB, Healy JK: Nephrotoxic effects of amphotericin B, including renal tubular acidosis. Am J Med 1969;46:154-162.

-22 McCurdy DK, Frederic M, Elkinton JR: Renal tubular acidosis due to amphotericin B. N Engl J Med 1968;278:124-130.
23 Burgess JL, Birchall R: Nephrotoxicity of amphotericin B, with emphasis on changes in tubular function. Am J Med 1972;53:77-84.

24 Smith SR, Galloway MJ, Reilly JT, Davies JM: Amiloride prevents amphotericin B related hypokalaemia in neutropenic patients. J Clin Pathol 1988;41:494-497.

25 Pathak A, Pien FD, Carvalho L: Amphotericin B use in a community hospital, with special emphasis on side effects. Clin Infect Dis 1998 26:334-338.

26 Walker RJ, Duggin GG: Drug nephrotoxicity. Annu Rev Pharmacol Toxicol 1988;28:331345.

27 Heyman SN, Stillman IE, Brezis M, Epstein FH, Spokes K, Rosen S: Chronic amphotericin nephropathy: Morphometric, electron microscopic, and functional studies. J Am Soc Nephrol 1993;4:69-80.

28 Albengres E, Le Louet H, Tillement JP: Systemic antifungal agents: Drug interactions of clinical significance. Drug Saf 1998;18:83-97.

29 Hoitsma AJ, Wetzels JF, Koene RA: Drug-induced nephrotoxicity: Aetiology, clinical features, and management. Drug Saf 1991;6:131147.

30 Cheng JT, Witty RT, Robinson RR, Yarger WE: Amphotericin B nephrotoxicity: Increased renal resistance and tubule permeability. Kidney Int 1982;22:626-633.

- 31 Fisher MA, Talbot GH, Maislin G, McKeon BP, Tynan KP, Strom BL: Risk factors for amphotericin B-associated nephrotoxicity. Am J Med 1989;87:547-552.

32 Stein RS, Alexander JA: Sodium protects against nephrotoxicity in patients receiving amphotericin B. Am J Med Sci 1989;298:299304.

33 Llanos A, Cieza J, Bernardo J, Echevarria J, Biaggoni I, Sabra R, Branch RA: Effect of salt supplementation on amphotericin B nephrotoxicity. Kidney Int 1991;40:302-308.

34 Chertow GM, Levy EM, Hammermeister KE, Grover F, Daley, J: Independent association between acute renal failure and mortality following cardiac surgery. Am J Med 1998;104 343-348.

35 Zager RA, O’Quigley J, Zager BK, et al: Acute renal failure following bone marrow transplantation: A retrospective study of 272 patients. Am J Kidney Dis 1989;13:210-216.

36 Coukell AJ, Brogden RN: Liposomal amphotericin B: Therapeutic use in the management of fungal infections and visceral leishmaniasis Drugs 1998;55:585-612.

37 Boswell GW, Buell D, Bekersky I: AmBisome (liposomal amphotericin B): A comparative review. J Clin Pharmacol 1998;38:583-592.

38 Walsh TJ, Finberg HV, Arndt C: Liposomal amphotericin B for empirical therapy in patients with persistent fever and neutropenia. $\mathrm{N}$ Engl J Med 1999;340:764-771.

39 Rex JH, Bennett JE, Sugar AM: A randomized trial comparing fluconazole with amphotericin $\mathrm{B}$ for the treatment of candidemia in patients without neutropenia. Candidemia Study Group and the National Institute. N Engl J Med 1994;331:1325-1330.
40 Polak A, Hartman PG: Antifungal chemotherapy - Are we winning? Prog Drug Res 1991; 37:181-269.

41 Walsh TJ, de Pauw B, Anaissie E, Martino P. Recent advances in the epidemiology, prevention and treatment of invasive fungal infections in neutropenic patients. J Med Vet Mycol 1994;32(suppl 1):33-51.

42 Bates DW, Su L, Yu DT: Mortality and costs of acute renal failure associated with amphotericin B therapy. Clin Infect Dis 2001;32: 686-693

43 Polak A: The past, present and future of antimycotic combination therapy. Mycoses 1999; 42:355-370.

44 Arevalo MP, Arias A, Andreu A: Fluconazole, itraconazole and ketoconazole in vitro activity against Candida spp. J Chemother 1994;6: 226-229.

45 Van't Wout JW: Fluconazole treatment of candidal infections caused by non-albicans Candida species. Eur J Clin Microbiol Infect Dis 1996;15:238-242.

46 Goa KL, Barradell LB: Fluconazole. An update of its pharmacodynamic and pharmacokinetic properties and therapeutic use in major superficial and systemic mycoses in immunocompromised patients. Drugs 1995;50:658-690.

47 Kaplan B, Rabinerson D, Gibor Y: Single-dose systemic oral fluconazole for the treatment of vaginal candidiasis. Int $\mathrm{J}$ Gynaecol Obstet 1997;57:281-286.

48 Finlay PM, Richardson MD, Robertson AG: A comparative study of the efficacy of fluconazole and amphotericin B in the treatment of oropharyngeal candidosis in patients undergoing radiotherapy for head and neck tumors. $\mathrm{Br}$ J Oral Maxillofac Surg 1996;34:23-25.

49 Perry CM, Whittington R, McTavish D: Fluconazole. An update of its antimicrobial activity, pharmacokinetic properties, and therapeutic use in vaginal candidiasis. Drugs 1995;49. 984-1006.

50 Anaissie E, Bodey GP, Kantarjan H: Fluconazole therapy for chronic disseminated candidiasis in patients with leukemia and prior amphotericin B therapy. Am J Med 1991;91: $142-150$.

51 Ikemoto H: A clinical study of fluconazole for the treatment of deep mycoses. Diagn Microbiol Infect Dis 1989; 12:2395-2475.

52 Rex JH, Bennett JE, Sugar AM, Pappas PG, van der Horst CM, Edwards JE, Washburn RG, Scheld WM, Karchmer AW, Dine AP, et al: A randomized trial comparing fluconazole with amphotericin B for the treatment of candidemia in patients without neutropenia. Candidemia Study Group and the National Institute. N Engl J Med 1994;331:1325-1330.

53 Debruyne D: Clinical pharmacokinetics of fluconazole in superficial and systemic mycoses. Clin Pharmacokinet 1997;33:52-77.

54 Samonis G, Roslton K, Karl C, Miller P, Bodey GP: Prophylaxis of oropharyngeal candidiasis with fluconazole. Rev Infect Dis 1990;12 (suppl 3):S369-S373. 
-55 Goodman JL, Winston DJ, Greenfield RA: A controlled trial of fluconazole to prevent fungal infections in patients undergoing bone marrow transplantation. N Engl J Med 1992;326:845851.

-56 Philpott-Howard JN, Wade JJ, Mufti GJ: Randomized comparison of oral fluconazole versus oral polyenes for the prevention of fungal infection in patients at risk of neutropenia. Multicentre Study Group. J Antimicrob Chemother 1993;31:973-984.

-57 Mucke R, Kaben U, Libera T: Fluconazole prophylaxis in patients with head and neck tumours undergoing radiation and radiochemotherapy. Mycoses 1998;41:421-423.

- 58 Van Burik JH, Leisenring W, Myerson D, Hackman RC, Shulman HM, Sale GE, Bowden RA, McDonald GB: The effect of prophylactic fluconazole on the clinical spectrum of fungal diseases in bone marrow transplant recipients with special attention to hepatic candidiasis. An autopsy study of 355 patients. Medicine 1998;77:246-254.

59 Longman LP, Hibbert SA, Martin MV: Efficacy of fluconazole in prophylaxis and treatment of experimental Candida endocarditis. Rev Infect Dis 1990;12(suppl 3):S294-S298.

60 Nguyen MH, Nguyen ML, Lu VL: Candida prosthetic valve endocarditis: Prospective study of six cases and review of the literature. Clin Infect Dis 1996;22:262-267.

61 Viscoli C, Castagnola E, Fioredda F: Fluconazole in the treatment of candidiasis in immunocompromised children. Antimicrob Agents Chemother 1991;35:365-367.

-62 Fasano C, O'Keefe J, Gibbs D: Fluconazole treatment of children with severe fungal infections not treatable with conventional agents. Eur J Clin Microb Infect Dis 1994;13:344347.

63 Flynn PM, Cunningham CK, Kerkering T, San Jorge AR, Peters VB, Pitel PA, Harris J, Gilbert G, Castagnaro L, Robinson P: Oropharyngeal candidiasis in immunocompromised children: A randomized multicenter study of orally administered fluconazole suspension versus nystatin. J Pediatr 1995; 127:322-328.

-64 Presterl E, Graninger W: Efficacy and safety of fluconazole in the treatment of systemic fungal infections in pediatric patients. Multicentre Study Group. Eur J Clin Microbiol Infect Dis 1994;13:347-351.

- 65 Cap J, Mojzesova A, Kayserova E, Bubanska E, Hatiar K, Trupl J, Krcmery V: Fluconazole in children: First experience with prophylaxis in chemotherapy-induced neutropenia in paediatric patients with cancer. Chemotherapy 1993;39:438-442.

66 Ninane J: A multicentre study of fluconazole versus oral polyenes in the prevention of fungal infection in children with hematological or oncological malignancies. Multicentre Study Group. Eur J Clin Microbiol Infect Dis 1994; 13:330-337.

-67 Driessen M, Ellis JB, Muwazi F, De Villiers FP: The treatment of systemic candidiasis in neonates with oral fluconazole. Ann Trop Paediatr 1997; 17:263-271.
68 Groll AH, Just-Nuebling G, Kurz M, Mueller C, Nowak-Goettel U, Schwabe B, Shah PM, Komhuber B: Fluconazole versus nystatin in the prevention of candida infections in children and adolescents undergoing remission induction or consolidation chemotherapy for cancer. J Antimicrob Chemother 1997;40: 885-862.

69 Wenzl TG, Schefels J, Hornchen H, Skopnik $\mathrm{H}$ : Pharmacokinetics of oral fluconazole in premature infants. Eur J Pediatr 1998;157:661662.

70 Martin MV: The use of fluconazole and itraconazole in the treatment of Candida albicans infections: A review. J Antimicrob Chemother 1999;44:429-437.

71 Haria M, Bryson HM, Goa KL: Itraconazole. A reappraisal of its pharmacological properties and therapeutic use in the management of superficial fungal infections. Drugs 1996;51: 585-620.

72 Rees T, Phillips R: Multicenter comparison of one-day oral therapy with fluconazole or itraconazole in vaginal candidiasis. Int J Gynaecol Obstet 1992;37(suppl 1):33S-38S.

73 Rongioletti F, Robert E, Tripodi S: Treatment of onychomycosis with itraconazole. J Dermatolog Treat 1992;2:145-146.

74 Hoang A: Caspofungin acetate: An antifungal agent. Am J Health Syst Pharm 2001;58:12061214

75 Keating GM, Jarvis B: Caspofungin. Drugs 2001;61:1121-1129.

76 Bartizal K, Gill CJ, Abruzzo GK, Flattery AM, Kong L, Scott PM, Smith JG, Leighton CE, Bouffard A, Dropinski JF, Balkovec J: In vitro preclinical evaluation studies with the echinocandin antifungal MK-0991. Antimicrob Agents Chemother 1997;41:2326-2332.

77 Groll AH, Gullick BM, Petraitiene R, Petraitis V, Candelario M, Piscitelli SC, Walsh TJ: Compartmental pharmacokinetics of the antifungal echinocandin caspofungin (MK-0991) in rabbits. Antimicrob Agents Chemother 2001;45:596-600.

78 Walsh T, Denning DW, Patterson IMF: Update of the multicentric uncomparative studies of caspofungin (abstract M 868). ICAAC 2002, San Diego, 27-30th September 2002.

79 Stone JA, Holland S, Li S: Effect of hepatic insufficiency on the pharmacokinetics of caspofungin (abstract A-14). 41st ICAAC, Chicago, 2001.

80 Villanueva A, Arathoon EG, Gotuzzo E, Berman RS: A randomized double-blind study of caspofungin versus amphotericin for the treatment of candidal esophagitis. Clin Infect Dis 2001;33:1529-1535.

81 Maertens J, Raad I: Multicenter, non-comparative study to evaluate safety and efficacy of caspofungin in adults with invasive aspergillosis refractory or intolerant to amphotericin $\mathrm{B}, \mathrm{AMB}$ lipid formulations, or azoles (abstract 1103). 40th ICAAC, Toronto, 2000.

82 Lin SJ, Schram J, Teutsch SM: Aspergillosis case-fatality rate: Systematic review of the literature. Clin Infect Dis 2001;32:358-366.
83 Mora-Duarte J, Betts R, Rotstein C, Colombo AL, Thompson-Moya L; Smietana J, Lupinacci R, Sable C, Kartsonis N, Perfect J; Caspofungin Invasive Candidiasis Study Group: Comparison of caspofungin and amphotericin B FOR invasive candidiasis. N Engl J Med 2002; 347:2020-2029.

84 Mora-Duarte J, Betts R, Rotstein C, Lopes-Colombo A: Caspofungin vs amphotericin $\mathrm{B}$ deoxycholate in the treatment of invasive candidiasis in neutropenic and nonneutropenic patients: A multi-centre, randomized, doubleblind study (abstract 0237). 12th ECCMID, Milan, 2002.

85 Hiemenz J, Raad I, Boogaerts M, Maertens J: Efficacy of caspofungin as salvage therapy for invasive aspergillosis compared to standard therapy in a historical cohort (poster 22). Focus on Fungal Infections 11, Washington, 2001.

86 Oakley KL, Moore CB, Denning DW: In vitro activity of voriconazole against Aspergillus spp. and comparison with itraconazole and amphotericin B. J Antimicrob Chemother 1998;42:91-94.

-87 Verweij PE, Mensink M, Rijs AJ, Donnelley JP, Meis JF, Denning DW: In vitro activities of amphotericin B, itraconazole, and voriconazole against 150 clinical and environmental Aspergillus fumigatus isolates. J Antimicrob Chemother 1998;42:389-392.

-88 Cuenca-Estrella M, Rodriguez-Tudela J-L, Mellado E: Comparison of the in vitro activity of voriconazole (UK-109,496), itraconazole and amphotericin $\mathrm{B}$ against clinical isolates of Aspergillus fumigatus. J Antimicrob Chemother 1998; 42:531-533.

89 Murphy M, Bernard EM, Ishimaru T, Armstrong D: Activity of voriconazole (UK109,496) against clinical isolates of Aspergillus species and its effectiveness in an experimental model of invasive aspergillosis. Antimicrob Agents Chemother 1997;41:696-698.

90 Martin MV, Yates J, Hitchcock CA: Comparison of voriconazole (UK-109,496) and itraconazole in prevention and treatment of Aspergillus fumigatus endocarditis in guinea pigs. Antimicrob Agent Chemother 1997;41:13-16.

91 George D, Miniter P, Andriole VT: Efficacy of UK-109,496, a new azole antifungal agent, in an experimental model of invasive aspergillosis. Antimicrob Agents Chemother 1996;40: 86-91.

92 Kirkpatrick WR, McAtee RK, Forthergill AW: Efficacy of voriconazole in a guinea pig model of disseminated invasive aspergillosis. Antimicrob Agents Chemother 2000;44:2865-2868.

93 Denning DW, Marinus A, Cohen J and the EORTC Invasive Fungal Infections Cooperative Group: An EORTC multicentre prospective survey of invasive aspergillosis in cancer patients: Diagnosis and therapeutic outcome. J Infect 1998;37:173-180.

94 Denning DW, Lee JY, Hostetler JS, Pappas P, Kauffman CA, Dewsnup DH, Galgiani JN, Graybill JR, Sugar AM, Catanzaro A, et al: NIAID Mycoses Study Group multicenter trial of oral itraconazole therapy for invasive aspergillosis. Am J Med 1994;91:135-144. 
95 Schwartz S, Milatovic D, Thiel E: Successful treatment of cerebral aspergillosis with a novel triazole (voriconazole) in a patient with acute leukaemia. Br J Haematol 1997;97: 663-665.

96 Denning DW, Ribaud P, Milpied N, Calliot D, Herbrecht R, Thiel E, Haas A, Ruhnke M, Lode H: Efficacy and safety of voriconazole in the treatment of acute invasive aspergillosis. Clin Infect Dis 2002;34:563-571.

-97 Herbrecht R, Denning DW, Patterson TF, Bennett JE, Greene RE, Oestmann JW, Kern WV, Marr KA, Ribaud P, Lortholary O, Sylvester R, Rubin RH, Wingard JR, Stark P, Durand C, Caillot D, Thiel E, Chandrasekar PH, Hodges MR, Schlamm HT, Troke PF, de Pauw B: Voriconazole versus amphotericin B for primary therapy of invasive aspergillosis. N Engl J Med 2002;347:408-415.

\$8 Walsh TJ, Pappas P, Winston DJ, Lazarus HM, Petersen F, Raffalli J, Yanovich S, Stiff P, Greenberg R, Donowitz G, Schuster M, Reboli A, Wingard J, Arndt C, Reinhardt J, Hadley S, Finberg R, Laverdiere M, Perfect J, Garber G, Fioritoni G, Anaissie E, Lee J: National Institute of Allergy and Infectious Diseases Mycoses Study Group. Voriconazole compared with liposomal amphotericin $B$ for empirical antifungal therapy in patients with neutropenia and persistent fever. N Engl J Med 2002;346:225-234.

-99 Law D, Moore CB, Denning DW: Activity of $5 \mathrm{CH} 56592$ compared with those of fluconazole and itraconazole against Candida spp. Antimicrob Agents Chemother 1997;41: 2310-2311.

100 Galgiani JN, Lewis ML: In vitro studies of activities of antifungal triazoles SCH56592 and itraconazole against Candida albicans, Cryptococcus neoformans, and other pathogenic yeasts. Antimicrob Agents Chemother 1997;41:180-183.

101 Espinel-Ingroff A: Comparison of in vitro activities of the new triazoles SCH56592 and the echinocandins MK-0991 (L-743,872) and LY303366 against opportunistic filamentous and dimorphic fungi and yeasts. J Clin Microbiol 1998;36:2950-2956.

- 102 Perfect JR, Cox GM, Dodge RK, Schell WA: In vitro and in vivo efficacy of the azole SCH56592 against Cryptococcus neoformans. Antimicrob Agents Chemother 1996;40: 1910-1913.

103 Oakley KL, Morrissey G, Denning DW: Efficacy of SCH-56592 in a temporarily neutropenic murine model of invasive aspergillosis with an itraconazole-susceptible and an itraconazole-resistant isolate of Aspergillus fumigatus. Antimicrob Agents Chemother 1997;41:1504-1507.
104 Lutz JE, Clemons KV, Aristizabal BH: Activity of the triazoles SCH 56592 against disseminated murine coccidioidomycosis. Antimicrob Agents Chemother 1997;41:15581561.

105 Graybill JR, Bocanegra R, Najvar LK: Granulocyte colony-stimulating factor and azole antifungal therapy in murine aspergillosis: role of Immune suppression. Antimicrob Agents Chemother 1998;42:2467-2473.

106 Graybill JR, Bocanegra R, Najvar LK: SCH56592 treatment of murine invasive aspergillosis. J Antimicrob Chemother 1998; 42:539-542.

107 Pfaller M: In vitro susceptibility of bloodstream isolates of rare Candida spp. against ravuconazole (abstract 1223). ICAAC, Chicago, September 14-17th , 2003.

108 Uchida K, Yokota N, Yamaguchi H: In vitro antifungal activity of pocasonazole against various pathogenic fungi. Int Antimcrob Agents 2001;18:167-172.

109 Ding JC, Bauer M, Diamond DM: Effect of severity of meningitis on fungicidal activity of flucytosine combined with fluconazole in a murine model of cryptococcal meningitis. Antimicrob Agents Chemother1997; 40: 2178-2182.

110 Larsen RA, Bozette SA, Jones BE: Fluconazole combined with flucytosine for treatment of cryptococcal meningitis in patients with AIDS. Clin Infect Dis 1994;19:741745.

111 Filler SG, Edwards JE: When and how to treat serious candidal infections: Concept and controversies. Curr Clin Top Infect Dis 1995; 15: $1-8$.

112 Graybill JR: Can we agree on the treatment of candidiasis? Clin Infect Dis 1997;25:60-63.

113 Graybill JR: The future of antifungal therapy. Clin Infect Dis 1996;22(suppl 2):166-177.

114 Pucetti P, Menacci A, Cencei E, Spaccapelo $\mathrm{R}$, Mosci P, Enssle KH: Cure of murine candidiasis by recombinant soluble interleukin. J Infect Dis 1994;269:1325.

115 Walsh TJ, Van Cutsem J, Polak A, Graybill JR: Immunomodulation and antifungal therapy of experimental invasive candidosis, histoplasmosis and aspergillosis: Recent advances and concepts. J Med Vet Mycol 1992; 30(suppl 1):223-240.

116 Rex JH, Walsh TJ, Sobel JD: Practice guidelines for the treatment of Candidiasis. Clin Infect Dis 2000;30:662-678.

117 EORTC International Antimicrobial Therapy Cooperative Group: Empiric antifungal therapy in febrile granulocytopenic patients. Am J Med 1989;86:668-672.

118 Annaissie EJ, Rex JH, Uzun O: Predictors of adverse outcome in cancer patients with candidaemia. Am J Med 1998;104:238-245.

-119 British Society for Antimicrobial Chemotherapy Working Party: Management of deep Candida infection in surgical and intensive care unit patients. Intensive Care Med 1994; 20:522-528.
120 Eggimann P, Francioli P, Bille J: Fluconazole prophylaxis prevents intra-abdominal candidiasis in high-risk surgical patients. Crit Care Med 1999;27:1066-1072.

121 Munoz P, Burillo A, Bouza E: Criteria used when initiating antifungal therapy against Candida spp. in the intensive care unit. Int $\mathrm{J}$ Antimicrob Agents 2000;15:83-90.

122 Fichtenbaum CJ, German M, Dunagan WC, Fraser VJ, Medoff G, Diego J, Powderly WG: A pilot study of the management of uncomplicated candidemia with a standardized protocol of amphotericin B. Clin Infect Dis 1999; 28:1551-1556.

123 Cap J, Mojzesova A, Kayserova E, Bubanska E, Hatiar K, Trupl J, Krcmery V Jr: Fluconazole in children: First experience with prophylaxis in chemotherapy-induced neutropenia in pediatric patients with cancer. Chemotherapy 1993;39:438-442.

124 Krcmery V, Soltes L, Cap J: Fluconazole in prevention of fungal infections in cancer children. Int J Clin Exp Chemother 1992;4:1315.

125 Fasano J: The use of fluconazole in children. Eur J Clin Microbiol Infect Dis 1993;10:12.

126 Huttova M, Filka J, Krcmery V: Fungal infections in neonates. J Publ Health 2001;4:133140.

127 Kossoff EH, Buescher ES, Karlowicz MG: Candidemia in a neonatal intensive care unit: Trends during fifteen years and clinical features of 111 cases. Pediatr Infect Dis J 1998; 17:504-508

128 Rowen JL, Tate JM: Management of neonatal candidiasis. Neonatal Candidiasis Study Group. Pediatric Infect Dis J 1998; 17:10071011.

129 Walsh TJ, Seidel NL, Arndt C, Hartus RE, Dinubile MJ, Reboli A, Hiemenz J, Chanock SJ: Amphotericin B lipid complex in pediatric patients with invasive fungal infections. Pediatr Infect Dis J 1999; 18:702-708.

130 Starke JR, Mason EO Jr, Kramer WG, Kaplan SL: Pharmacokinetics of amphotericin B in infants and children. J Infect Dis 1987; 155:766-774.

131 Chen YC, Chang SC, Luh KT, Hsieh WC: Stable susceptibility of Candida blood isolates to fluconazole despite increasing use during the past 10 years. J Antimicrob Chemother 2003;52:71-77.

132 Canton E, Peman J, Viudes A, Quindos G, Gobernado M, Espinel-Ingroff A: Minimum fungicidal concentrations of amphotericin $\mathrm{B}$ for bloodstream Candida species. Diagn Microbiol Infect Dis 2003;45:203-206.

133 Steinbach WJ, Perfect JR: Newer antifungal therapy for emerging fungal pathogens. Int $\mathrm{J}$ Infect Dis 2003; 7:5-20. 